\title{
Observations on the Kveim reaction using an animal model of granulomatous bowel disease
}

\author{
I C Mitchell, J L Turk
}

\begin{abstract}
Striking differences were observed between the visceral and cutaneous responses after tests with validated Kveim and normal spleen suspensions in a guinea pig model of granulomatous bowel disease. Five of six animals sensitised with BCG showed positive responses at the ileal Kveim test site whereas all six had negative cutaneous Kveim tests. Conversely, two of six animals sensitised with irradiated Mycobacterium leprae showed positive cutaneous Kveim tests and only one a positive response in the ascending colon. All six showed negative responses at the ileal Kveim test site. No positive visceral or cutaneous responses were observed in either group of animals after tests with normal spleen suspension. These findings are discussed in relation to the positive Kveim responses previously reported among patients with Crohn's disease, tuberculoid and lepromatous leprosy, and among seemingly healthy BCG vaccinated subjects. The findings provide further evidence in support of a possible mycobacterial aetiology for sarcoidosis and Crohn's disease.
\end{abstract}

We have recently reported a model of epithelioid and primarily macrophage infiltration in the bowel wall and draining lymph nodes of the guinea pig, induced by the direct inoculation of quantified amounts of BCG (Pasteur) and irradiated Mycobacterium leprae into the wall of the alimentary tract. Our findings with this model in relation to the aetiology of Crohn's disease and the effects upon the granulomatous infiltrates of a variety of immune modulating agents has been discussed previously. ${ }^{12}$

A wide variability in the number of granulomatous reactions has been reported in response to Kveim tests among patients with Crohn's disease $^{34}$ and other granulomatous diseases such as leprosy. ${ }^{5-7}$ We have used this consistent and reproducible model to investigate the effects induced by the visceral and cutaneous inoculation of a human sarcoid spleen suspension shown to have a substantial degree of specificity for sarcoidosis and a suspension prepared identically from a normal human spleen.

Methods

ANIMALS

Outbred Hartley strain female guinea pigs weighing 300 to $430 \mathrm{~g}$ were used. They were fed on a rabbit, guinea pig pellets diet supplemented with cabbage.

\section{MYCOBACTERIA}

Live BCG was of Pasteur strain obtained by courtesy of the Institut Pasteur, Paris. Cobalt irradiated armadillo derived $M$ leprae was obtained courtesy of Dr R J W Rees, National Institute for Medical Research, Mill Hill, London. The Mycobacteria were obtained as a suspension in saline. The BCG organisms were counted by the method of Miles and Misra ${ }^{8}$ for viable organisms. $M$ leprae was counted by the method of Hart and Rees, ${ }^{9}$ which gives a count of the total number of intact organisms. Live $M$ leprae was not used because of legal restrictions owing to its pathogenicity in man.

\section{SARCOID SPLEEN SUSPENSION}

Both sarcoid and normal human spleen suspensions were obtained by courtesy of Dr D N Mitchell, the Brompton Hospital, London. The former was derived from a single lot (Lot 1) of a Type I, Chase Siltzbach ${ }^{10}$ test suspension of a sarcoid spleen K51. This had previously been extensively validated in man, alongside suspensions already shown to have a high degree of selectivity for sarcoidosis, and yielded the expected proportion of granulomatous reactions among these patients, but a negligible number among patients with other conditions.

NORMAL HUMAN SPLEEN SUSPENSION

This was from a single lot of Type I normal spleen suspension which yielded a negligible proportion of relatively feeble granulomatous responses in reactive sarcoid patients when tested alongside $\mathrm{K} 51$ and other validated sarcoid spleen suspensions. The latter yielded the expected granulomatous responses.

\section{LAPAROTOMY}

This was performed using a procedure developed by the authors and fully described in a previous publication.' Briefly, animals were anaesthetised and using an aseptic technique, laparotomy was performed via a midline incision. This approach gives ready access to the terminal ileum. The abdomen was closed using Vicryl sutures (Ethicon UK, Ltd), the skin closure being reinforced with Histoacryl tissue adhesive (B Braun Melsungen AG, West Germany).

\section{INOCULATION OF MYCOBACTERIA}

All inoculations were of $50 \mu \mathrm{l}$ and standard doses of organisms were used - namely $2 \times 10^{7} \mathrm{BCG}$ and 
$2 \times 10^{9}$ irradiated $M$ leprae. Inoculation was performed using a Hamilton microlitre syringe and a $32 \mathrm{G}$ needle into the serosa of the antimesenteric wall of the bowel at the level of the terminal ileal Peyer's patch. The doses used were based upon earlier work ${ }^{1}$ in which they produced a satisfactory granulomatous infiltration in the terminal ileum and its draining lymph nodes and induced sensitivity to $25 \mu \mathrm{g}$ of purified protein derivative of tuberculin on skin testing.

\section{INOCULATION OF SARCOID AND NORMAL SPLEEN SUSPENSIONS}

At laparotomy and immediately after the inoculation of the Mycobacteria $0 \cdot 1 \mathrm{ml}$ of the required suspension was injected via a $26 \mathrm{G}$ needle, through which the particulate material freely passed, into the serosa of the terminal ileum $10 \mathrm{~cm}$ proximal to the ileocaecal junction and into the first $1 \mathrm{~cm}$ of the ascending colon. Care was taken not to allow mycobacterial contamination of these sites. A further $0.15 \mathrm{ml}$ of the test suspension was inoculated into the skin overlying the left ear at the end of the procedure.

Using this animal model, we have previously shown that maximal granulomatous responses after the inoculation of BCG or of irradiated $M$ leprae into the bowel wall accrue after intervals of 14 and 35 days respectively. 'Thus, the further Kveim tests which were injected into the right ear and pararectally after 14 days in the BCG inoculated animals or after 35 days in those receiving irradiated $M$ leprae and the Kveim or normal spleen suspensions which had been injected into the bowel wall immediately after the inoculation of the mycobacterial antigens at laparotomy were permitted a similar incubation period of 28 days after maximal mycobacterial sensitisation before harvesting.

Control animals received $0.1 \mathrm{ml}$ of Lot $\mathrm{K} 51$ into the test site on the terminal ileum only.

The inoculation sites, both visceral and cutaneous, were identified with a single tattoo speck of autoclaved Pelikan ink to facilitate subsequent macroscopic and histological identification of the sites.

\section{HARVESTING}

Animals inoculated with BCG were killed at 42 days and those receiving irradiated $M$ leprae were killed at 63 days. Control animals receiving only sarcoid spleen suspension (Lot K51) were har-

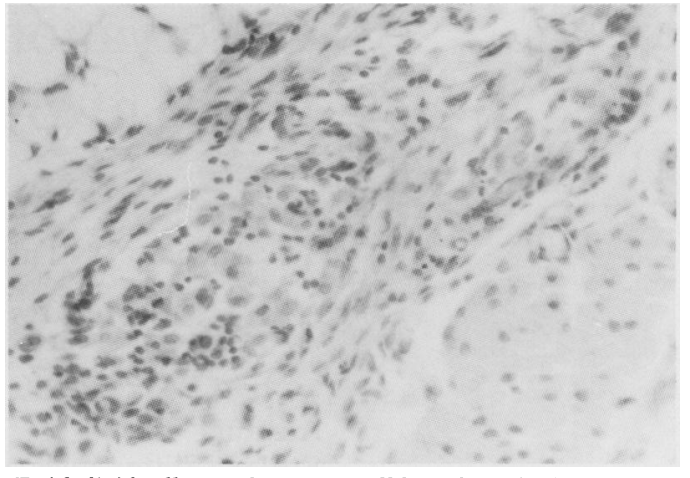

Epithelioid cell granuloma at small bowel Kveim inoculation site 42 days after injection of Kveim material and sensitisation with BCG. (Haematoxylin and eosin, original magnification $\times 125)$.

vested at 28 days. The abdomen was then reopened via the original incision. After macroscopic inspection the inoculation sites were excised, trimmed, and placed in $10 \%$ formol saline. Specimens for light microscopy were processed in a standard manner, embedded in wax and representative $5 \mu \mathrm{m}$ sections cut. The coded sections were read by the same observer (ICM) and demarcated as negative or positive depending upon the presence of granulomas on haematoxylin and eosin staining at the Kveim inoculation sites.

\section{Results}

The results are summarised in the Table. Animals inoculated with BCG showed an epithelioid cell response (Figure) at the marked ileal site after 42 days in five of six animals injected with Kveim suspension $\mathrm{K} 51$, and in one of six given normal spleen suspension. None of the BCG inoculated animals showed a response at any of the other Kveim injection sites. One of six animals inoculated with irradiated $M$ leprae showed a similar granulomatous response at the marked ascending colonic Kveim injection site after an interval of 63 days. At 63 days after inoculation of the Mycobacteria two of these animals also showed an epithelioid cell granulomatous response to Kveim material injected in the right ear 28 days previously. There were no other positive results at any other injection site.

\section{Discussion}

We have investigated the visceral and cutaneous

Visceral and cutaneous responses after Kveim tests in guinea pigs sensitised with BCG and irradiated Mycobacterium leprae

\begin{tabular}{|c|c|c|c|c|c|c|c|c|c|c|c|c|c|c|c|c|c|c|c|c|c|c|}
\hline \multirow{4}{*}{$\begin{array}{l}\text { Nature of } \\
\text { inoculum }\end{array}$} & & & \multicolumn{20}{|c|}{ Test site/suspension/result } \\
\hline & & & \multicolumn{4}{|c|}{ Ileum } & \multicolumn{4}{|c|}{ Ascending colon } & \multicolumn{4}{|c|}{ Left ear } & \multicolumn{4}{|c|}{ Right ear } & \multicolumn{4}{|c|}{ Perianal } \\
\hline & \multicolumn{2}{|c|}{ Interval (days) } & \multicolumn{2}{|c|}{$K 51$} & \multicolumn{2}{|c|}{$N S$} & \multicolumn{2}{|c|}{$K 51$} & \multicolumn{2}{|c|}{ NS } & \multicolumn{2}{|c|}{$K 51$} & \multicolumn{2}{|c|}{$N S$} & \multicolumn{2}{|c|}{ K5I } & \multicolumn{2}{|c|}{$N S$} & \multicolumn{2}{|c|}{$K 51$} & \multicolumn{2}{|c|}{$N S$} \\
\hline & Pre-test & Test/harvest & $P$ & $N$ & $P$ & $N$ & $P$ & $N$ & $P$ & $N$ & $P$ & $N$ & $P$ & $N$ & $P$ & $N$ & $P$ & $N$ & $P$ & $N$ & $P$ & $N$ \\
\hline \multirow{5}{*}{$\begin{array}{l}2 \times 10^{7} \\
\text { BCG } \\
\text { Total } \\
2 \times 10^{4} \\
\text { Irradiated } \\
\text { M leprae } \\
\text { Total }\end{array}$} & \multirow{2}{*}{$\begin{array}{r}0 \\
14\end{array}$} & \multirow{2}{*}{$\begin{array}{l}42 \\
28\end{array}$} & 5 & 1 & 1 & 5 & 0 & 6 & 0 & 6 & 0 & 6 & 0 & 6 & \multirow{3}{*}{$\begin{array}{l}0 \\
0\end{array}$} & \multirow{3}{*}{$\begin{array}{l}6 \\
6\end{array}$} & \multirow{3}{*}{$\begin{array}{l}0 \\
0\end{array}$} & \multirow{3}{*}{$\begin{array}{l}6 \\
6\end{array}$} & \multirow{3}{*}{$\begin{array}{l}0 \\
0\end{array}$} & \multirow{3}{*}{$\begin{array}{l}6 \\
6\end{array}$} & \multirow{3}{*}{\multicolumn{2}{|c|}{$\begin{array}{ll}0 & 6 \\
0 & 6\end{array}$}} \\
\hline & & & 5 & 1 & 1 & 5 & 0 & 6 & 0 & 6 & 0 & 6 & 0 & 6 & & & & & & & & \\
\hline & 0 & 63 & 0 & 6 & 0 & 6 & 1 & 5 & 0 & 6 & 0 & 6 & 0 & 6 & & & & & & & & \\
\hline & 35 & 28 & & & & & & & & & & & & & 2 & 4 & 0 & 6 & 0 & 6 & 0 & 6 \\
\hline & & & 0 & 6 & 0 & 6 & 1 & 5 & 0 & 6 & 0 & 6 & 0 & 6 & 2 & 4 & 0 & 6 & 0 & 6 & 0 & 6 \\
\hline
\end{tabular}

$\mathrm{P}=$ positive $\mathrm{N}=$ negative.

$\mathrm{K} 5 \mathrm{l}=$ = Kveim suspension; $\mathrm{NS}=$ normal spleen suspension 
responses resulting from the injection of Kveim and normal spleen suspensions in an experimental animal model of granuloma formation in the bowel wall of the guinea pig. These bowel lesions were induced by the inoculation of BCG and irradiated $M$ leprae into the serosa of the ileum overlying the terminal ileal Peyer's patch.

It has thus been possible to compare the reactions to these reagents in the immediately proximal ileum, ascending colon, perianal mucosa, and the skin at different times among animals sensitised with either BCG or M leprae. Epithelioid cell granulomas resulting from the injection of these reagents were largely confined to ileal Kveim test sites among the BCG vaccinated animals. In this context it is relevant to note that BCG was inoculated into the most distal terminal ileal Peyer's patch or the most proximal Peyer's patch of the ascending colon, whereas the Kveim suspension was injected into the serosa of the terminal ileum $10 \mathrm{~cm}$ proximal to the ileocaecal junction or into the first $1 \mathrm{~cm}$ of the ascending colon. ${ }^{1}$ Thus, it is extremely unlikely that the positive ileal Kveim responses could be accounted for by preferential drainage of mycobacterial products to the ileal rather than to the colonic test sites. A possible alternative explanation for this finding may be provided by the fact that in this guinea pig model of granulomatous bowel disease, the area of infiltration in the ileum was significantly less than that in the ascending colon for a given mycobacterial load and that, as judged by Ziehl-Neelsen staining of tissues from the inoculation sites, acid fast bacilli were present in the colonic but not in the small bowel tissues.' The latter finding suggests possible differences in the handling of Mycobacteria in these areas of bowel which may also account for the differences in responsiveness to the Kveim suspension.

In our previous description of this model of granulomatous bowel infiltration, it was noted that both the Mycobacteria induced a significant response to purified protein derivative of tuberculin at 14 days after sensitisation in the case of BCG and, to a lesser extent, at 35 days using $M$ leprae.' Our present findings may therefore be compared with previous studies in the context of BCG vaccination, of tuberculin sensitivity, and Kveim testing in man. In a study of 25 healthy subjects" given BCG vaccination either recently or in the past and who showed conversion to tuberculin sensitivity, five gave a granulomatous response to a Kveim test with a well validated suspension, Lot 8 of New York spleen J. Likewise, of 12 healthy subjects who showed no evidence of tuberculin conversion after a previous and more recent BCG vaccination, each yielding good scars, seven gave a granulomatous response on testing with the same Kveim suspension. As none of the subjects showed any evidence of clinical abnormality it was concluded that a possible explanation was a normally slight tendency to become Kveim reactive after BCG inoculation, which underlying tendency was accentuated among those failing to convert to tuberculin positivity.

Our finding of Kveim reactivity in the skin in two of six guinea pigs inoculated with irradiated $M$ leprae 35 days previously and in the ascending colon of one animal at an interval of 65 days may be considered in a similar context. Previous studies of the Kveim test, ${ }^{72}$ both using Lot 8 of spleen J, report granulomatous reactions in two of 15 patients with lepromatous leprosy in Japan, and in nine with tuberculoid and 21 with lepromatous leprosy among predominantly Chinese patients in Malaysia.

We encountered a single granulomatous reaction in the ileum of one of six animals inoculated with BCG 40 days after testing with a normal spleen suspension. This had previously been shown to yield a negligible proportion of feeble granulomatous responses in skin tests among reactive patients with sarcoidosis. It is, however, relevant that although tests of other normal spleen and lymph node suspensions ${ }^{13}$ have shown no response, other workers ${ }^{1+15}$ have reported that two of 12 normal spleen suspensions tested produced a response in patients with sarcoidosis who were reactive to sarcoid spleen suspensions.

Crohn's disease shares with sarcoidosis the granulomatous element in its histology, but evidence of an impaired response to tuberculin skin testing ${ }^{16-18}$ was not shown when the responses were compared with those in matched control subjects. ${ }^{19}$ Skin testing with Candida albicans and Trichophyton also failed to differentiate Crohn's disease patients from healthy subjects. ${ }^{20}$ Kveim tests performed with a Kveim suspension, Lot 5 of spleen $\mathrm{K} 12,{ }^{321}$ which had been validated against Lot 10 of spleen $\mathrm{J}$, in 74 patients with Crohn's disease showed a granulomatous response in $51 \%$. Other workers, however, found no granulomatous response after Kveim tests with Lot 10 of spleen J and Lot 1 of spleen $\mathrm{K} 12$ in 16 patients with Crohn's disease.

Mycobacterial infection may be related to granulomatous changes in the bowel wall without the consistent finding of acid fast bacilli either on microscopy or culture using our present techniques. Recent reports of the finding of previously unrecognised acid fast bacilli among patients with inflammatory bowel disease $^{22} 23$ are relevant in this context.

Kveim test suspensions are prepared from deep frozen sarcoid spleen or lymph node materials. The active component of a validated Kveim suspension is as yet unknown, but the processing of reactive and selective spleens and of normal spleens that are inactive but of a similar dry weight indicates that the active component constitutes only a very small proportion of the sarcoid spleen suspension. Recent reports of the detection of tuberculostearic acid in the lymph nodes of patients with sarcoidosis ${ }^{24}$ may be explained by the presence of either Mycobacteria not cultivable using present techniques or the remnants from a previous mycobacterial colonisation.

The results of our studies using this experimental animal model of granulomatous bowel disease have shown striking differences between visceral and cutaneous Kveim reactivity and a relative selectivity of ileal Kveim responsiveness. Our findings support the view that further studies using a system of RNA extraction from affected bowel and lymph node tissues linked with a system of the highly sensitive techniques 
of DNA/RNA hybridisation may be relevant to further studies of the possible role of $\mathrm{Myco}$ bacteria in the aetiology and pathogenesis of Crohn's disease and sarcoidosis.

The authors wish to thank Miss M Jacques, Mr F Schindler, and Mr P Papasavva for their excellent technical assistance and Mrs J Saxby for typing the manuscript. They also gratefully acknowledge the financial support of the Lilian May Coleman Fund of the Royal College of Surgeons of England.

1 Mitchell IC, Turk JL. An experimental animal model of ranulomatous bowel disease. Gut 1989 30: 1371-8.

2 Mitchell IC, Turk JL. Effect of the immune modulating agents cyclophosphamide, methotrexate, hydrocortisone and cyclosporin A on an animal model of granulomatous bowel disease. Gut 1990; 31: 674-8.

3 Mitchell DN, Cannon P, Dyer NH, Willoughby JMT. Further observations on Kveim test in Crohn's disease. Lancet 1970; 2: 496-9.

4 Siltzbach LE, Vieira LOBD, Topilsky M, Janowitz HD. Is there Kveim responsiveness in Crohn's disease? Lancet $1971 ; 2: 634-6$.

5 Wade HW. Leprosy and sarcoid; Kveim test in leprosy patients and contacts. F Invest Dermat 1951; 17: 337-47.

6 Celikoglu SI, Siltzbach LE. A study of sarcoidosis and leprosy in Turkey employing the Kveim reaction. Dis Chest 1969 55: $400-4$

7 Pearson JMH, Pettit JMS, Siltzbach LE, Ridley DS, Har PD'A, Rees RJW. The Kveim test in lepromatous and tuberculoid leprosy. Int $\mathcal{F}$ Lepr 1960; 37: 372-81.

8 Miles AA Misra SS. The estimation of the bacterial power of the blood. F Hyg 1938; 38: 732-48.

9 Hart PD'A, Rees RJW. Effect of macrocyclon in acute and chronic pulmonary tuberculous infection in mice as shown by viable and total bacterial counts. Br $\mathcal{F}$ Exp Pathol 1960 ; 41: 414-21.
10 Chase MW. The preparation and standardization of Kveim testing antigen. Am Rev Respir Dis 1961; 84: 86-8.

11 Hart PD'A, Mitchell DN, Sutherland I. Associations between Kveim test results, previous BCG vaccination, and tuberculin sensitivity in healthy young adults. $B M \mathcal{F} 1964$; $\mathrm{i}$ 795-804.

12 Siltzbach LE. An international Kveim test study (1960-1966) In: Turiaf J, Chabot J, eds. La sarcoidose. Paris: Masson, 1967: 201-13.

13 Siltzbach LE, Ehrlich JC. The Nickerson-Kveim reaction in sarcoidosis. Am F Med 1954, 16: 790-803.

14 Nelson CT Observations on the Kyeim reaction in sarcoidosis of the American negro. F Invest Dermatol 1948; 10: 15-26.

15 Nelson CT. Kveim reaction in sarcoidosis. Arch Dermatol Nelson CT. Kveim reaction in
Syphilol NY 1949; 60: 377-89.

16 Blackburn G, Hadfield G, Hunt AH. Regional ileitis. St Bar Hosp Rep 1939; 72: 181-224.

17 Phear DN. The relation between regional ileitis and sarcoidosis. Lancet 1958; ii: 1250-1.

18 Williams WJ. A study of Crohn's syndrome using tissue extracts and the Kveim and Mantoux tests. Gut 1965; 6: 503-5.

19 Fletcher J, Hinton JM. Tuberculin sensitivity in Crohn's disease. A controlled study. Lancet 1967; ii: 753-4.

20 Binder HJ, Spiro HM and Thayer WR. Delayed hypersensitivity regional enteritis and ulcerative colitis. $A m \mathcal{f} D i g D$ is 1966; $11: 572-4$

21 Mitchell DN, Cannon P, Dyer NH, Hinson KFW, Willoughby JMT. The Kveim test in Crohn's disease. ancet 1969; ii: 571-3.

22 Graham DY, Markesich DC, Yoshimura HH. Mycobacteria and inflammatory bowel disease. Results of culture. Gastroenterology 1987 92: 436-42.

23 Chiodini RJ, Van Kruiningen HJ, Thayer WR, Merkal RS Coutu JA. Possible role of mycobacteria in inflammatory bowel disease. 1. An unclassified Mycobacterium species isolated from patients with Crohn's disease. Dig Dis Sci 1984 29: 1073-9.

24 Hanngren A Odham C, Eklund A, Hoffner S, Stjernberg N, Westerdahl $G$. Tuberculostearic acid in lymph nodes from patients with sarcoidosis. Sarcoidosis 1987; 4: 101-4. 